\title{
Agôn
}

Revue des arts de la scène

Critiques | Saison 2012-2013

\section{Les Trois Scurs de Tchekhov, mise en scène de Lev Dodine}

« Où est-il parti, tout mon passé ?»

\section{Alice Carré}

\section{CpenEdition}

\section{Journals}

Édition électronique

URL : http://journals.openedition.org/agon/1680

DOI : 10.4000 /agon. 1680

ISSN : 1961-8581

Éditeur

Association Agôn

Référence électronique

Alice Carré, "Les Trois Sœurs de Tchekhov, mise en scène de Lev Dodine », Agôn [En ligne], Critiques, mis en ligne le 21 novembre 2012, consulté le 23 septembre 2020. URL : http://

journals.openedition.org/agon/1680; DOI : https://doi.org/10.4000/agon.1680

Ce document a été généré automatiquement le 23 septembre 2020.

Association Agôn et les auteurs des articles 


\section{Les Trois Sœurs de Tchekhov, mise en scène de Lev Dodine}

«Où est-il parti, tout mon passé ? "

\section{Alice Carré}

\section{RÉFÉRENCE}

Les Trois Sœurs de Tchekhov, mise en scène de Lev Dodine. Présenté dans le cadre du Prix Europe pour le théâtre à Saint Petersburg en Avril 2011, Théâtre Maly. Repris du 16 au 21 novembre 2012 à la MC 93, Bobigny.

1 Lev Dodine, directeur du théâtre Maly à Saint-Petersbourg a engagé un profond dialogue avec l'œuvre d'Anton Tchekhov, avec non moins de cinq spectacles consacrés aux pièces les plus célèbres de l'auteur dont La Mouette, La Cerisaie et Oncle Vania. La quatorzième édition du Prix Europe pour le théâtre, qui avait récompensé le metteur en scène en 2000, proposait un retour sur Les Trois Sœurs, créé en 2010, avant que le spectacle n'entreprenne une tournée en à New York et en France. 
Les Trois Sœurs de Tchekhov, mise en scène de Lev Dodine

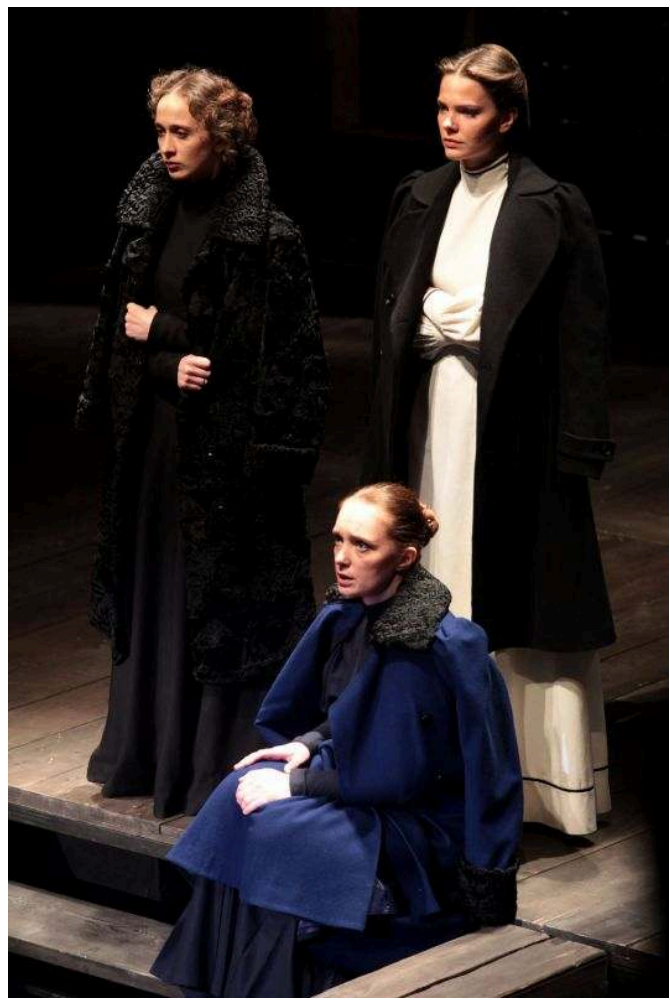

(C)Rossetti

2 Cette connaissance intime et profonde de l'univers tchekhovien amène Dodine à placer le spectacle dans un rythme sans précipitation, un brin ralenti, qui cherche à restituer la sensation du temps qui passe et emporte avec lui les illusions des personnages. Il est ainsi quelques instants de pause où l'image se fige, comme lorsqu'Irina, la plus jeune des trois sœurs, lance la toupie qu'elle a reçue pour sa fête. La spirale tournoyante est à l'image du temps, passant et emportant avec lui les rêves de changement. Ce que nous montre Dodine, c'est le spectacle de la communauté impuissante, suspendue au tourbillon de ce jouet, ces habitants d'une ville de province russe ne rêvant que de rejoindre Moscou. Le plateau présente donc la vie dans sa réalité la plus simple, faite de ces instants d'errance où l'âme s'égare. Cette succession délicate des répliques ne fait cependant jamais sombrer le spectacle dans l'ennui, car la mise en scène sait préserver la vitalité des « courants souterrains » chers à Nemirovitch-Dantchenko, co-fondateur avec Stanislavski du théâtre d'Art de Moscou, qui jalonnent l'œuvre de Tchekhov. Le texte apparaît dans toute sa finesse, grâce à la mise en lumière de certains détails qui sont souvent seulement suggérés: la grossesse de Natacha avant qu'Andreï ne la demande en mariage, le désir d'olga pour le mari de sa sœur Macha. Ainsi, les relations entre les personnages sont rendues à merveille par un jeu d'une grande précision, fidèle au ressenti prôné par la méthode Stanislavki qui a marqué profondément la formation de l'acteur en Russie. Irina, incarnée par la magnifique Elisaveta Boyarksaya, véritable célébrité du cinéma et du théâtre russe, semble être au cœur de cette lecture, elle est la plus jeune des sœurs, celle qu'on voit le plus lutter pour ne pas laisser s'échapper son rêve d'une vie nouvelle : sa lente résignation est au cœur de la pièce. Elle cède et fléchit au fil des actes et laisse partir, comme par abandon, celui qui l'aime 
passionnément, dans un duel où elle le sait condamné. Les acteurs se cantonnent à un jeu épuré, mais qui fait naître l'émotion sans la forcer.

3 À l'image de ce temps qui passe, la façade de la maison familiale s'avance acte après acte, réduisant ainsi l'espace libre du plateau et l'espoir d'évasion qu'il offrait. Ainsi, la disparition du passé est rendue matériellement, et le cri du frère Andreï à l'acte IV résonne avec force : «Où est-il, où est-il parti, tout mon passé, quand j'étais jeune, gai, intelligent, quand mes rêves et mes pensées touchaient à tout ce qui est beau et élevé, quand mon présent et mon avenir étaient éclairés d'espoir?».

4 Tchekhov lui-même reprochait à Stanislavski d'avoir ralenti le rythme des Trois Sœurs au point de transformer en tragédie, ce qu'il avait écrit comme une comédie. Lev Dodine se serait sans doute attiré les foudres de l'auteur, mais il ne rate aucun des moments drôles et absurdes de la pièce et donne à cette vision mélancolique du monde une sorte de douceur irréversible, à l'image des lumières rasantes qui viennent caresser la peau des acteurs et s'infiltrent dans les planches du décor. De cette épure naît également l'absurde, et l'on reste captivé par ce mot, inscrit par le professeur Kouligine sur le mur de la maison: "bêtise». Tout n'est que bêtise, à l'image de ces vies insignifiantes, accrochant un rire cynique à leur désespoir. 